\title{
PREDICCIÓN DE LAS NECESIDADES HÍDRICAS CON UNA SEMANA DE ANTELACIÓN MEDIANTE TELEDETECCIÓN Y METEOROLOGÍA EN LA FINCA EXPERIMENTAL CENTER PARA CULTIVOS DE MAÍZ.
}

\author{
Garrido-Rubio, J. (1) (P), González Gómez, L. (1), Arellano Alcazar, I. (1), Madurga del Cura, \\ C. (2), Navarro Comalrena de Sobregrau, M. (3), López Tapia, J. (3) Calera Belmonte, A. (4)
}

\begin{abstract}
1 Ingeniero Agrónomo, Sección de Teledetección y SIG, Instituto de Desarrollo Regional, Universidad de Castilla-La Mancha, C. Campus Universitario s/n 02071, Albacete, España. Jesus.Garrido@uclm.es; Laura.Gonzalez@uclm.es; Irene.Arellano@uclm.es

2 Responsable Asistencia Técnica CENTER, Grupo Tragsa - SEPI, C/ Maldonado, 58, 28006, Madrid, España. cmadurga@tragsa.es

${ }^{3}$ Subdirección General de Regadíos y Economía del Agua (SGRYEA), Dirección General de Desarrollo Rural y Política Forestal (DGDRPF), Secretaría General de Agricultura y

Alimentación, Ministerio de Agricultura, Alimentación y Medio Ambiente. C/ Gran Vía de San Francisco, 28005, Madrid, España.mnacomal@magrama.es; jtapia@magrama.es

${ }^{4}$ Director, Sección de Teledetección y SIG, Instituto de Desarrollo Regional, Universidad de Castilla-La Mancha, C. Campus Universitario s/n 02071, Albacete, España.

Alfonso.Calera@uclm.es
\end{abstract}

\section{Resumen}

Determinar las necesidades hídricas que los cultivos demandarán a corto plazo juega un papel fundamental en la gestión de explotaciones agrícolas de regadío. De su precisión depende la obtención de mejores rendimientos productivos, económicos y medioambientales. La experiencia llevada a cabo en la finca experimental de la DGDRPF CENTER del MAGRAMA, obtuvo la predicción de las necesidades hídricas con una semana de antelación durante todo el periodo de monitorización. Basados en la ecuación del coeficiente de cultivo único $\left(\mathrm{K}_{\mathrm{c}}\right)$, de la metodología $\mathrm{FAO56}$, se predijo la evapotranspiración del cultivo $\left(E T_{c}\right)$ en parcelas de maíz en regadío. Para ello, se emplearon técnicas meteorológicas que predijeron la evapotranspiración de referencia $\left(E T_{0}\right)$, y técnicas de teledetección basadas en secuencias temporales de índices de vegetación (IV) mediante las cuales se predijo el $\mathrm{K}_{\mathrm{c}}$. Los resultados obtenidos produjeron una ligera sobre estimación de la $\mathrm{ET}_{\mathrm{c}}$ a final de campaña (8\%). Paralelamente, los riegos aplicados fueron validados externamente mediante el empleo de sondas de humedad. En resumen, la experiencia proporcionó resultados adecuados con un bajo número de recursos. Así, la programación del riego se realizó mediante la combinación de técnicas de teledetección y meteorológicas.

\section{1- Introducción}

La planificación del riego a la escala temporal de una semana es un aspecto de gran interés en el manejo de los cultivos por parte de los agricultores, pues permite la planificación de la aplicación de agua de riego de forma óptima teniendo en cuenta la disponibilidad de agua, del sistema de riego, y otros factores como la tarificación eléctrica, etc... Para ello, es necesario estimar las necesidades de agua del cultivo con una semana de antelación. Dado que las necesidades de agua se pueden calcular como el producto del $\mathrm{K}_{\mathrm{c}}$ y la $\mathrm{ET}_{\mathrm{o}}$, ambos parámetros deben ser estimados con el horizonte temporal señalado. 
Actualmente, la metodología más extendida para su estimación es mediante el producto $\mathrm{K}_{\mathrm{c}}$, extraído de valores tabulados normalmente zonificados, y la $\mathrm{ET}_{\mathrm{o}}$, determinada mediante estaciones meteorológicas. Sin embargo, hoy en día, la teledetección presenta un estado de madurez óptimo para monitorizar cultivos debido a la frecuencia de revisita de los satélites y su consiguiente generación de series temporales de imágenes multiespectrales. Consecuentemente, mediante productos derivados de dichas imágenes se obtienen los índices de vegetación, los cuales pueden ser relacionados de forma lineal con los $\mathrm{K}_{\mathrm{c}}$. Por tanto, mediante el presente trabajo se da un paso más en la monitorización de cultivos y se muestra la metodología empleada en obtener la predicción de sus necesidades hídricas para la semana siguiente. Para ello, se realiza la predicción semanal tanto del $\mathrm{K}_{\mathrm{c}}$ derivado de imágenes de satélite, como de la ETo derivada de las temperaturas previstas. La experiencia tuvo lugar durante la campaña de verano 2014 sobre cultivos de maíz en la finca experimental de la DGDRPF - CENTER, donde semanalmente se facilitó la predicción de las necesidades hídricas con la que programar el riego.

\section{2- Descripción}

La experiencia tuvo lugar en la finca experimental del CENTER (San Fernando de Henares, Madrid), sobre 3 parcelas en regadío bajo diferentes sistemas de riego y cultivadas con maíz. Las características de las parcelas y los cultivos quedan recogidas en la siguiente Figura 1 de localización y en la Tabla 1 de descripción.

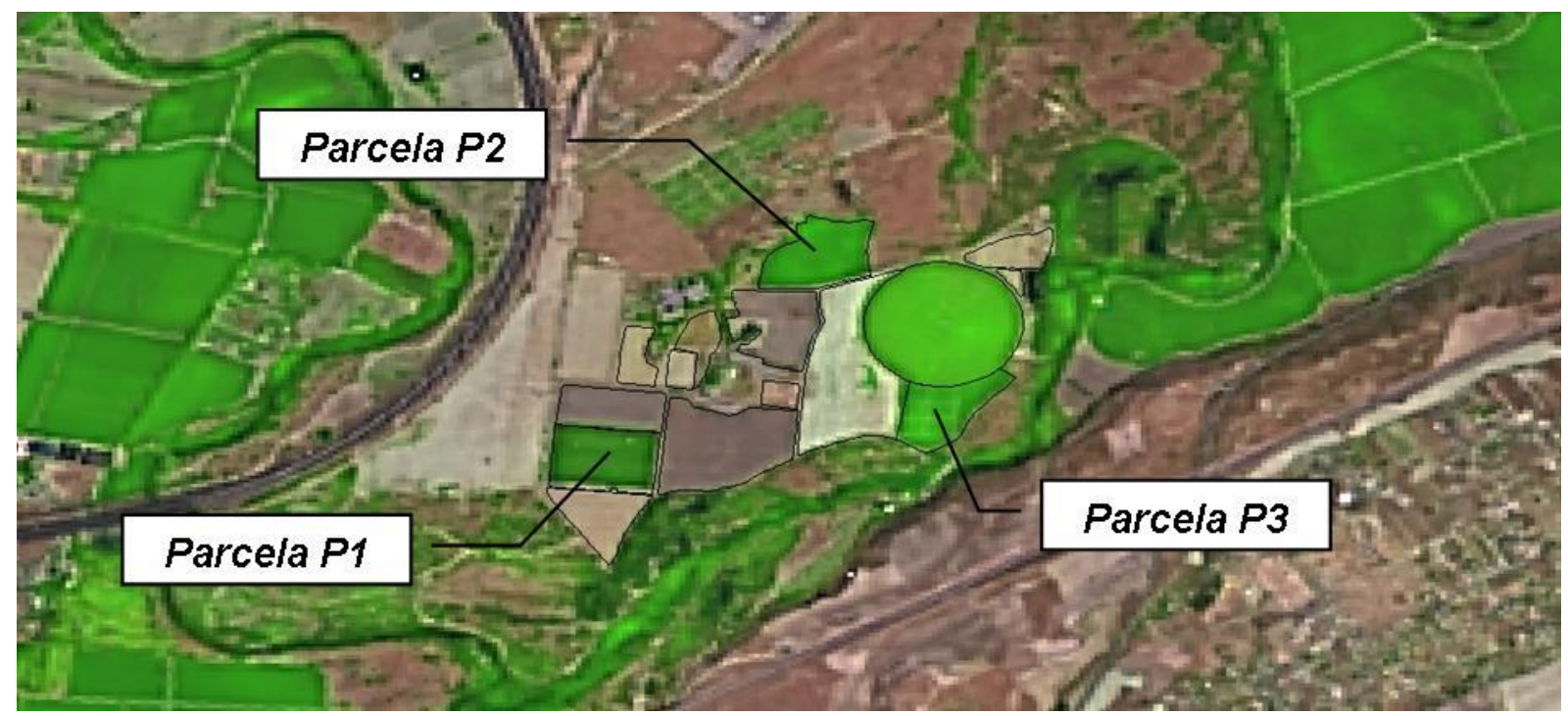

Figura 1. Vista general de las parcelas del CENTER monitorizadas durante la experiencia, usando una imagen RGB Landsat 8 con fecha 05 de Agosto de 2014.

Tabla 1. Características de las parcelas empleadas en la experiencia

\begin{tabular}{|c|c|c|c|c|c|c|}
\hline Parcela & $\begin{array}{c}\text { Superficie } \\
\text { cultivada (ha) }\end{array}$ & $\begin{array}{c}\text { Densidad de } \\
\text { siembra (uds./ha) }\end{array}$ & $\begin{array}{c}\text { Sistema de } \\
\text { riego }\end{array}$ & $\begin{array}{c}\text { Fecha de } \\
\text { siembra }\end{array}$ & $\begin{array}{c}\text { Fecha de } \\
\text { cosecha }\end{array}$ & $\begin{array}{c}\text { Sonda de } \\
\text { humedad }\end{array}$ \\
\hline P1 & 6,00 & 95.000 & Gravedad & 10 Mayo & 30 Octubre & $\mathrm{Si}$ \\
\hline P2 & 6,38 & 95.000 & Aspersión & 8 Mayo & 31 Octubre & $\mathrm{Si}$ \\
\hline P3 & 5,80 & 95.000 & Aspersión & 29 Abril & 31 Octubre & No \\
\hline
\end{tabular}

El periodo de monitorización tuvo lugar desde el 18 de junio al 2 de octubre del 2014. Durante este tiempo se proporcionó una ficha semanal con la predicción de las necesidades 
hídricas de la siguiente semana, de tal forma que fuese posible la programación de los riegos a 7 días vista. Dichas fichas contenían por parcela la predicción de la $E T_{0}$, la extrapolación del $\mathrm{K}_{\mathrm{c}}$ y la determinación de las necesidades hídricas o $\mathrm{ET}_{\mathrm{c}}$. Recalcar que estas necesidades no contemplaron las eficiencias de los diferentes sistemas de riego.

Para llevar a cabo la estimación de las necesidades hídricas de la cubierta vegetal, se empleó la metodología coeficiente de cultivo único - evapotranspiración de referencia $\left(\mathrm{K}_{\mathrm{c}}\right.$ - ETo), descrita de forma detallada en el manual de FAO56 (Allen et al., 1998). Esta metodología determina la $\mathrm{ET}_{\mathrm{c}}$ bajo condiciones estándar, por lo que se considera que no existen limitaciones en el desarrollo del cultivo debidas al estrés hídrico entre otras. El método de cálculo establecido en la ecuación 1 ( $\mathrm{mm} / \mathrm{semana})$, consiste en el producto de dos factores. El primero, la $\mathrm{ET}_{\mathrm{o}}$, considera la demanda evaporativa y engloba parámetros meteorológicos como la radiación, la velocidad del viento y la sequedad del aire. El segundo, el $\mathrm{K}_{\mathrm{c}}$, indica el estado de desarrollo de una cubierta vegetal frente a otra considerada de referencia, en FAO56 la festuca. En consecuencia, para realizar la predicción debemos operar cada factor de forma independiente para luego combinarlos en dicha ecuación.

$$
\text { 1. } E T_{c}=K_{c} \cdot E T_{o}
$$

\section{1- Predicción semanal de la $\mathrm{ET}_{\mathrm{o}}$ mediante meteorología}

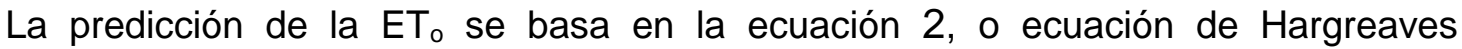
(Hargreaves and Samani, 1985). Esta ecuación es la recomendada cuando sólo se disponen de datos de temperatura, en lugar de emplear la ecuación de Penman-Monteith que es hasta la fecha la más adecuada y usada diariamente (Allen et al., 1998). Esta ecuación, expresada en $\mathrm{mm} / \mathrm{d}$ ía, tiene en cuenta únicamente variables de temperatura media $\left(T_{\text {med }}\right)$, máxima $\left(T_{\max }\right)$, mínima $\left(T_{\min }\right)$ y la radiación extraterrestre $\left(R_{a}\right)$. Operativamente, para predecir de forma semanal la $\mathrm{ET}_{0}$ se emplea la predicción de temperaturas diarias máximas y mínimas con alcance semanal que la Agencia Estatal de Meteorología pone a disposición del público a nivel municipal (AEMeT). Por consiguiente, la suma de las previsiones diarias de $\mathrm{ET}_{\text {o }}$ proporciona la predicción semanal.

$$
\text { 2. } E T_{o}=0,0023 \cdot\left(T_{\text {media }}+17,8\right) \cdot\left(T_{\text {max }}-T_{\text {min }}\right)^{0,5} \cdot R_{a}
$$

\section{2- Predicción del $\mathrm{K}_{\mathrm{c}}$ mediante teledetección}

Durante la experiencia se procesaron 14 imágenes: 9 Landsat 8 OLI y 5 Landsat 7 ETM+ (Figura 2). La presencia de nubes a lo largo de toda la campaña fue notable, y durante septiembre no se pudo disponer de ninguna imagen. La adquisición gratuita y descarga libre fueron posibles gracias al portal "Glovis" adscrito y mantenido por el United States Geological Service (USGS, http://glovis.usgs.gov/). La escena de trabajo fue la 200031. Recalcar, que al contar con dos satélites se pudo disponer durante el mes de julio y agosto de una imagen por semana, lo que redujo la problemática de las nubes.

El empleo de imágenes multiespectrales capturadas por sensores a bordo de satélites permite obtener índices de vegetación desde los que estimar el $\mathrm{K}_{c}$ de una cubierta vegetal. El índice de vegetación empleado es el NDVI (Rouse et al., 1973). Es un índice comúnmente empleado en teledetección que mide el tamaño fotosintético relativo de la cubierta. Es un parámetro robusto, simple y sencillo de obtener mediante la combinación algebraica de las reflectividades en el rojo e infrarrojo cercano. Para un uso correcto de los valores de NDVI es necesario proporcionar las reflectividades corregidas en superficie, es decir, hay que corregir atmosféricamente para eliminar el efecto atenuante que tiene la atmósfera sobre la señal recibida. Así, se llevó a cabo una normalización absoluta en cada 
imagen de NDVI (Campos et al., 2011). Además, esta corrección atmosférica permite incluir imágenes procedentes de diferentes sensores. Así mismo, el procesado de las imágenes pasó previamente por una corrección radiométrica (Chander et al., 2009). Paralelamente se generó el producto combinación color, junto con el NDVI, para la carga y visualización de las imágenes en el visor WebSIG SPIDER-CENTER Riego. La Figura 2 muestra la evolución temporal del NDVI por parcela (la caída del valor NDVI para la fecha 20 de Julio se corresponde con la presencia de una nube).
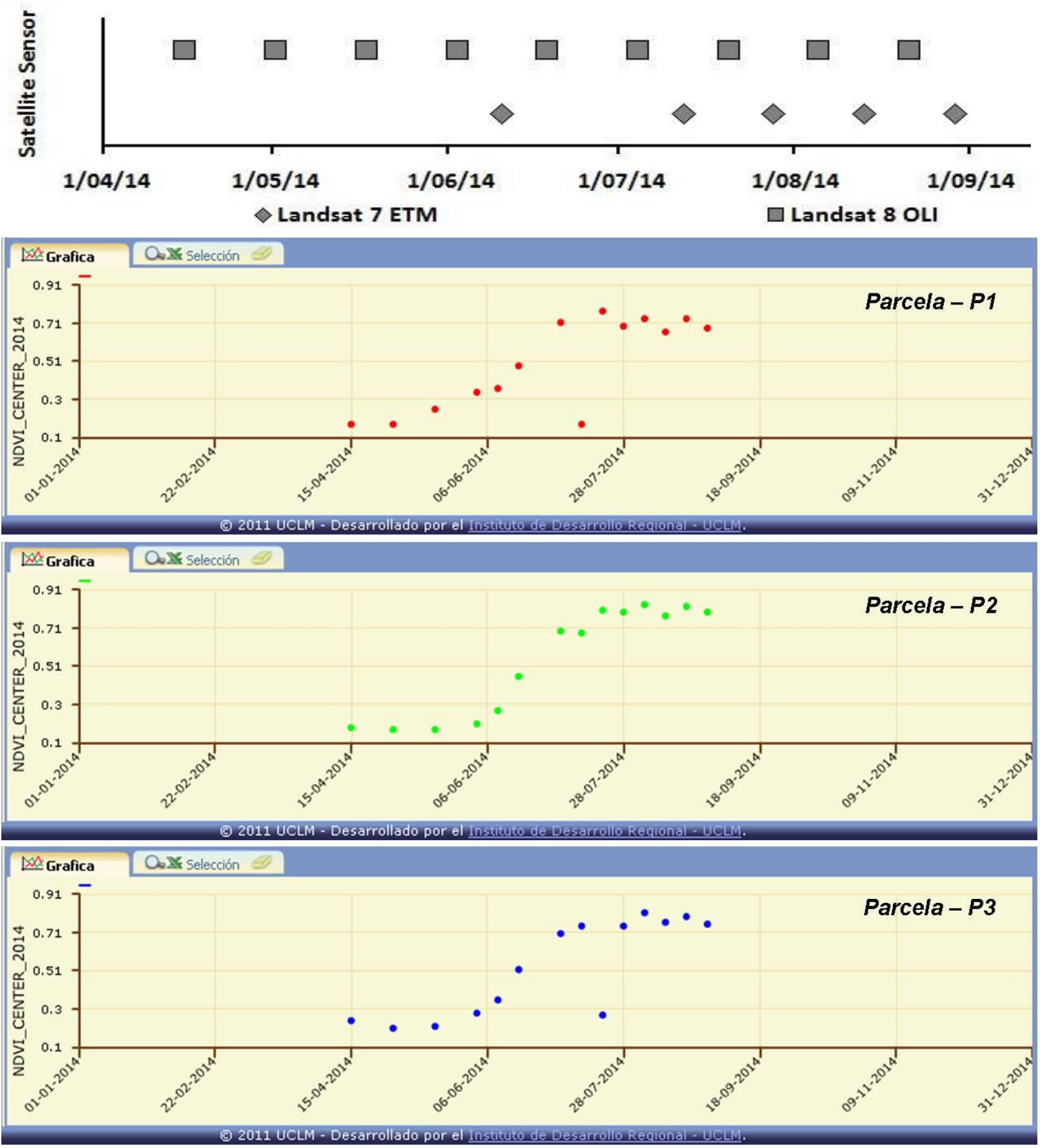

Figura 2. De arriba abajo: calendario de adquisición y procesado de las imágenes de satélite empleadas Landsat 8 OLI y Landsat 7 ETM+; y evolución temporal del NDVI para las parcelas P1, P2 y P3 respectivamente tal cual se visualizan en el visor WebSIG SPIDER-

CENTER Riego (http://zeus.idr-ab.uclm.es/publico/webgis/). 
Finalmente, una vez obtenido el NDVI es posible derivar el $\mathrm{K}_{\mathrm{c}}$ mediante una relación lineal (NDVI - $\mathrm{K}_{\mathrm{c}}$ ) mostrada en la ecuación 3 (Cuesta et al., 2005). Dicha ecuación ha sido ampliamente validad en cultivos herbáceos como trigo, cebada, maíz, algodón, girasol,...que en su fase de maduración alcanzan la cobertura completa y suponiendo un manejo estándar para sistemas de riego como aspersión y pívot. Por consiguiente, la forma de predecir el $\mathrm{K}_{\mathrm{c}}$ es mediante una extrapolación temporal lineal a la fecha central de la semana siguiente de predicción empleando las últimas imágenes disponibles. Por ello, se seleccionaron por parcela un conjunto de píxeles representativos por cada fecha y se obtuvo el promedio del NDVI. A continuación se aplica la ecuación 3, y proporciona un valor extrapolado promedio de $\mathrm{K}_{\mathrm{c}}$ por parcela

$$
\text { 3. } K_{c}=1,25 \cdot N D V I+0,2
$$

\section{3- Evaluación de los resultados}

La evaluación de los resultados se realizó al final de la experiencia. En este apartado la evaluación es dividida desde un punto de vista general, donde se engloba todo el proceso de monitorización, y desde una perspectiva semanal. A nivel global, los resultados mostrados en la Figura 3 se corresponden con la evaluación de la predicción del $\mathrm{K}_{\mathrm{c}}$ y la $E T_{\text {o }}$ según los siguientes criterios.
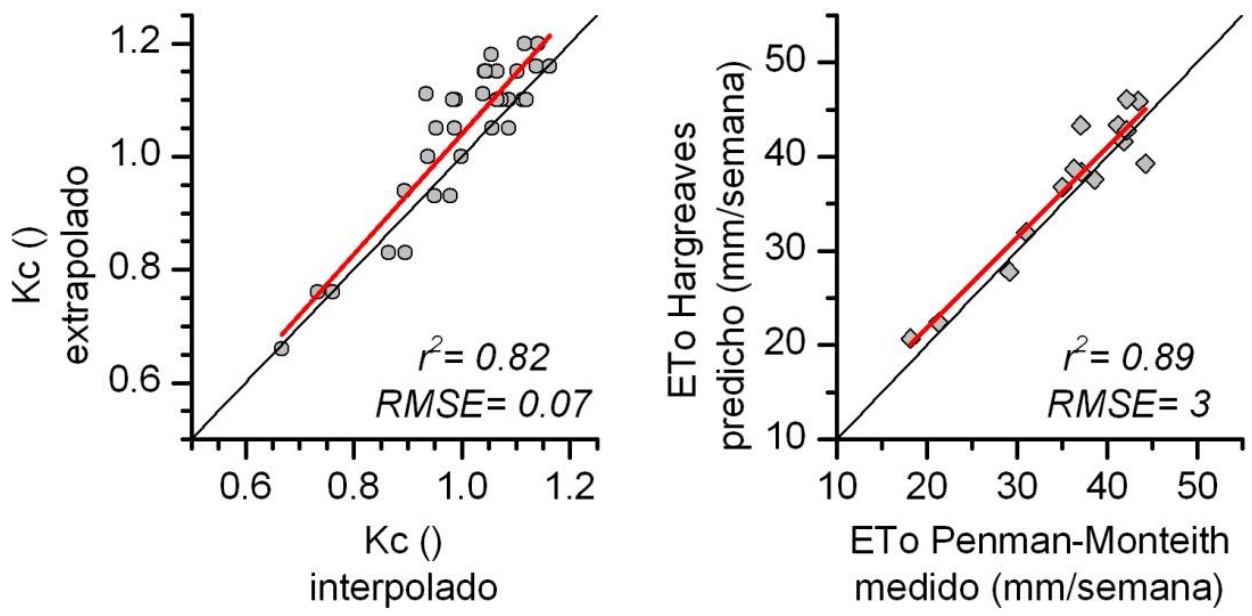

Figura 3. Comparación: (izquierda) $\mathrm{K}_{\mathrm{c}}$ extrapolado e interpolado obtenido mediante teledetección; (derecha) ET。 predicho por Hargreaves y medido por Penman-Monteith.

En relación al $\mathrm{K}_{\mathrm{c}}$ extrapolado, su evaluación se realiza según el $\mathrm{K}_{\mathrm{c}}$ interpolado a la misma fecha que el extrapolado. En relación a la $\mathrm{ET}_{\mathrm{o}}$, los valores predichos son comparados con los valores medidos empleando la metodología de Penman-Monteith. Dichos valores fueron recogidos por la estación agroclimática ubicada en la propia finca experimental del CENTER que pertenece a la red del Sistema de Información Agroclimática para el Regadío, red SIAR (MAGRAMA, 2014). En detalle, ambas comparaciones muestran que a lo largo del periodo de monitorización se extrapolaron valores de $\mathrm{K}_{c}$ y predijeron valores de $E T_{0}$ superiores a los que posteriormente se interpolaron o midieron respectivamente. Si bien, el error medio cuadrático (RMSE) por semana en ambos casos resulta ser bajo, en el caso del $\mathrm{K}_{\mathrm{c}}$ los errores cometidos son ligera y cualitativamente superiores a los errores producidos por la predicción de la $\mathrm{ET}_{\mathrm{o}}$.

A nivel semanal, la Tabla 2 y la Figura 4 muestran los resultados que se entregaron al CENTER a lo largo del periodo de monitorización para realizar la programación de riegos. 
De forma común a las 3 parcelas de estudio, la $\mathrm{ET}_{\text {o }}$ predicha y medida es la misma. Así, a final del periodo de monitorización la $\mathrm{ET}_{\text {o }}$ predicha superó en $16 \mathrm{~mm}$ a la medida. Además, de forma general, los mayores errores se cometieron al comienzo de la experiencia, en la primera y segunda semana.

Tabla 2. Resultados por parcela y semana de predicción de las diferentes componentes que se suministraron semanalmente al CENTER para gestionar la programación de riegos.

\begin{tabular}{|c|c|c|c|c|c|c|c|c|c|c|c|c|c|c|}
\hline \multirow{3}{*}{$\begin{array}{l}\text { Semana } \\
\text { (año 2014) }\end{array}$} & \multicolumn{7}{|c|}{ Valores predichos } & \multicolumn{7}{|c|}{ Valores estimados } \\
\hline & \multicolumn{3}{|c|}{$\mathrm{K}_{\mathrm{c}}()$} & \multirow{2}{*}{$\begin{array}{c}E T_{0} \\
(\mathrm{~mm})\end{array}$} & \multicolumn{3}{|c|}{$\mathrm{ET}_{\mathrm{c}}(\mathrm{mm})$} & \multicolumn{3}{|c|}{$\mathrm{K}_{\mathrm{c}}()$} & \multirow{2}{*}{$\begin{array}{c}E T_{0} \\
(\mathrm{~mm})\end{array}$} & \multicolumn{3}{|c|}{$E T_{c}(m m)$} \\
\hline & P1 & P2 & P3 & & P1 & P2 & P3 & P1 & P2 & P3 & & P1 & P2 & P3 \\
\hline $18 / 06-25 / 06$ & 0,77 & 0,60 & 0,67 & 43 & 33 & 26 & 29 & 0,73 & 0,67 & 0,76 & 37 & 27 & 25 & 28 \\
\hline 26/06-02/07 & 0,94 & 0,83 & 0,71 & 39 & 37 & 32 & 28 & 0,89 & 0,86 & 0,89 & 44 & 39 & 38 & 39 \\
\hline 03/07-09/07 & 1,00 & 1,11 & 1,11 & 38 & 38 & 42 & 42 & 1,00 & 0,99 & 0,98 & 39 & 39 & 39 & 38 \\
\hline 10/07-17/07 & 1,18 & 1,11 & 1,15 & 46 & 55 & 51 & 53 & 1,05 & 1,04 & 1,04 & 43 & 45 & 45 & 45 \\
\hline 18/07-23/07 & 1,10 & 1,16 & 1,16 & 43 & 48 & 50 & 50 & 1,09 & 1,14 & 1,16 & 41 & 45 & 47 & 48 \\
\hline 24/07-30/07 & 1,11 & 1,20 & 1,20 & 46 & 51 & 55 & 55 & 0,93 & 1,12 & 1,14 & 42 & 39 & 47 & 48 \\
\hline $31 / 07-06 / 08$ & 0,93 & 1,10 & 1,10 & 42 & 40 & 47 & 47 & 0,98 & 1,11 & 1,12 & 42 & 41 & 47 & 47 \\
\hline 07/08-13/08 & 1,00 & 1,10 & 1,10 & 43 & 43 & 47 & 47 & 0,94 & 1,07 & 1,07 & 42 & 39 & 45 & 45 \\
\hline $14 / 08-20 / 08$ & 0,93 & 1,05 & 1,05 & 38 & 36 & 42 & 42 & 0,95 & 1,09 & 1,06 & 37 & 35 & 40 & 39 \\
\hline $27 / 08-27 / 08$ & 1,05 & 1,15 & 1,15 & 39 & 41 & 45 & 45 & 0,99 & 1,10 & 1,07 & 36 & 36 & 40 & 38 \\
\hline 28/08-03/09 & 1,05 & 1,15 & 1,15 & 37 & 39 & 42 & 42 & 0,95 & 1,05 & 1,04 & 35 & 33 & 37 & 37 \\
\hline 04/09-10/09 & 0,94 & 1,07 & 1,07 & 32 & 30 & 34 & 34 & - & - & - & 31 & - & - & - \\
\hline $11 / 09-17 / 09$ & 1,04 & 1,04 & 1,04 & 28 & 29 & 29 & 29 & - & - & - & 29 & - & - & - \\
\hline Total & - & - & - & 514 & $461^{*}$ & $479^{*}$ & $480^{*}$ & - & - & - & 498 & 419 & 448 & 452 \\
\hline
\end{tabular}

* Los valores totales de $E T_{c}$ predichas no contienen las dos últimas semanas al no disponer de imágenes para estimar la $E T_{c}$.

Se comentan a continuación los resultados parcela a parcela. En el caso de la parcela $\mathrm{P} 1$, las necesidades de riego recomendadas fueron $42 \mathrm{~mm}$ superiores al final de la campaña, esto en, un $10 \%$ sobre el total estimado de $419 \mathrm{~mm}$. Concretamente, las semanas con mayores errores son la semana 4 y la 6 . Dichos máximos semanales en la $E T_{c}$ coinciden con las mayores diferencias que se observan en el $\mathrm{K}_{\mathrm{c}}$ (valores superiores de 0,13 y 0,18 en ambas semanas respectivamente). En relación a la parcela $\mathrm{P} 2$ la $\mathrm{ET}_{\mathrm{c}}$ predicha al final de la campaña supera en $31 \mathrm{~mm}$ a la finalmente estimada, esto es, un 7\% frente a los $448 \mathrm{~mm}$ finales. De nuevo, la sexta semana presenta una mayor desviación en las recomendaciones de riego aunque en este caso ni el $\mathrm{K}_{\mathrm{c}}$ extrapolado, ni la $\mathrm{ET}_{\text {o }}$ predicha, presentan los mayores errores a lo largo del periodo. Por último, la parcela P3 tuvo nuevamente unas recomendaciones de riego superiores a las estimadas. Sin embargo en esta ocasión, tan sólo alcanzaron los $28 \mathrm{~mm}$ a lo largo de toda la campaña, esto es un $6 \%$ más del total de $452 \mathrm{~mm}$. Ahora bien, en este caso, el mayor error es cometido por defecto en la semana 2, donde el $\mathrm{K}_{\mathrm{c}}$ se infra estimó al igual que la $\mathrm{ET}_{\mathrm{o}}$.

De forma general, en la evolución temporal mostrada en la Figura 4, se observan mayores errores durante las primeras 6 semanas de monitorización y predicción, es decir, desde finales de junio y durante todo el mes de julio. Este periodo de tiempo es crítico por 


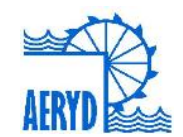

dos factores. El primero de ellos está relacionado con la $E T_{0}$, puesto que el mes de julio es históricamente donde se producen mayores $\mathrm{ET}_{0}$ diarias, y por lo tanto semanales. Si bien, el análisis mensual de los últimos 10 años en la misma estación SIAR muestra valores diarios promediados de 5,8 y $6,5 \mathrm{~mm}$ para los meses de junio y julio, mientras que en agosto, estos valores de $\mathrm{ET}_{\text {}}$ promediada diaria cae a $5,5 \mathrm{~mm}$. En consecuencia, los errores producidos en este mes tendrán mayor peso sobre el cálculo de las necesidades hídricas. En segundo lugar, el ciclo del cultivo del maíz suele llegar a meseta tras 70 días desde su plantación (Allen et al., 1998). Esto coincide con la primera semana de julio en P3 y con la tercera semana de julio en P1 y P2. Por ello, existe un punto de inflexión en la evolución del $\mathrm{K}_{\mathrm{c}}$ que difícilmente puede ser recogida por una extrapolación temporal lineal. Así, estos dos factores combinados, hacen que el periodo más crítico de predicción sea a durante el mes de julio, tal y como se ha visto anteriormente, pues mayores errores se han cometido.
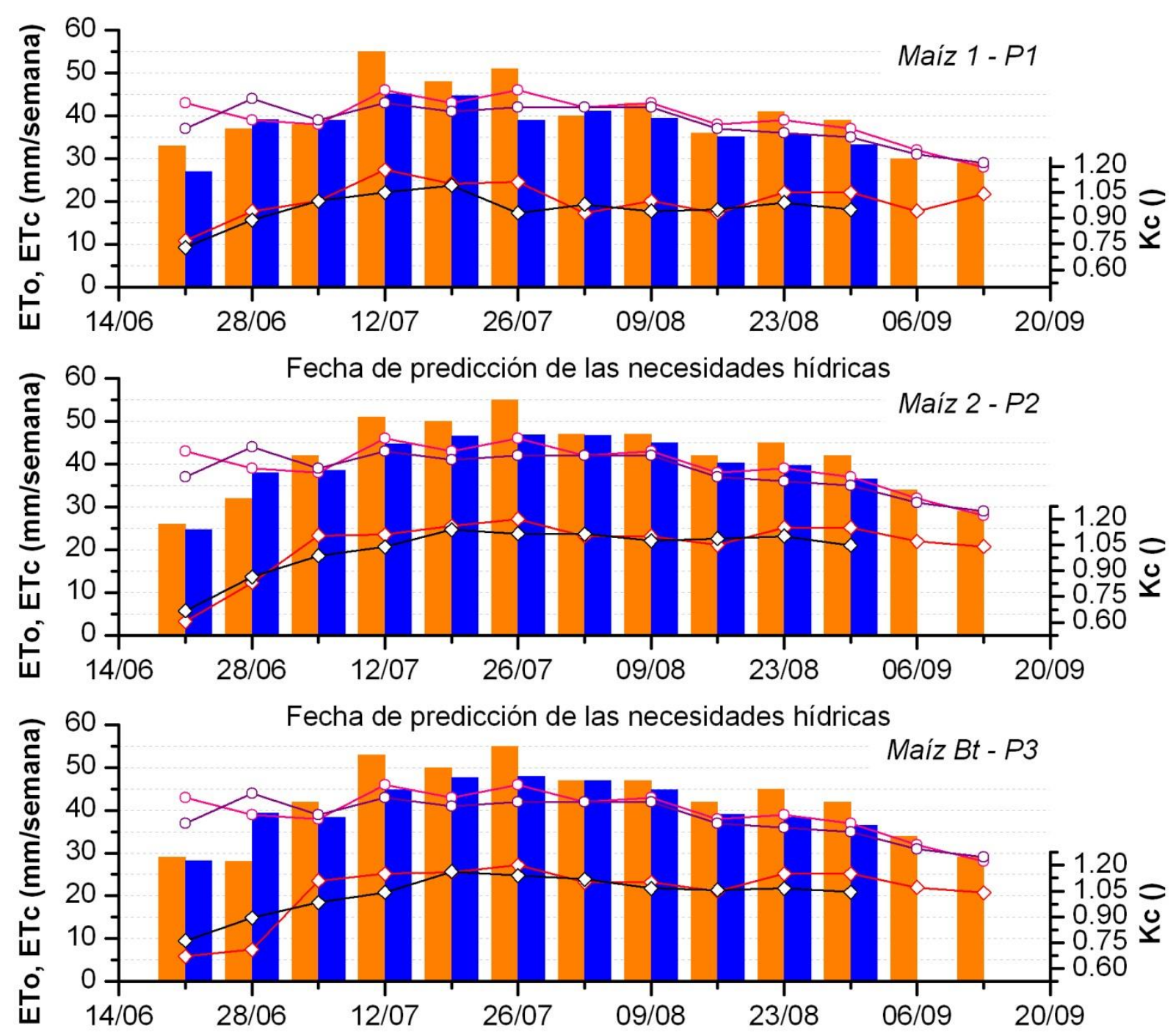

Fecha de predicción de las necesidades hídricas

$$
\begin{aligned}
& \text { ETc predicha } \multimap \text { ETo predicha } \multimap \text { Kc extrapolado } \\
& \text { ETc estimada } \multimap \text { ETo medida } \multimap \text { Kc interpolado }
\end{aligned}
$$

Figura 4. Comparación por parcela de estudio de: necesidades hídricas $\left(E T_{c}\right)$ predichas y estimadas; evapotranspiración de referencia $\left(\mathrm{ET}_{\mathrm{o}}\right)$ predicha y real; y coeficiente de cultivo único $\left(\mathrm{K}_{\mathrm{c}}\right)$ extrapolado e interpolado. Nota: Los valores semanales de $\mathrm{ET}_{\mathrm{c}}$ estimada no contienen las dos últimas semanas al no disponer de imágenes durante septiembre. 


\section{1- Evaluación externa de las dosis de riego recomendadas}

La validación externa se realizó mediante sondas de humedad instaladas en las parcelas P1 y P2. Su lectura de la humedad quedó limitada a los primeros $30 \mathrm{~cm}$. En la Figura 5 se puede observar la evolución temporal durante el periodo de monitorización de la humedad promedio en relación con el agotamiento de agua en el suelo, los riegos aplicados y los eventos de precipitación. Estas últimas tres variables se obtuvieron tras la realización de un balance de agua en el suelo asistido por teledetección (Garrido-Rubio et al., 2012; Torres, 2010), una vez obtenida completamente la serie temporal de imágenes NDVI e incorporando el calendario de riegos que finalmente proporcionó el CENTER.

En general se encontró un buen ajuste, especialmente en la parcela P2 donde se archivó un mayor número de registros. Ambas sondas muestran evoluciones de humedad que siguen un comportamiento plano en la mayoría del periodo de monitorización, lo que indicaría una buena adecuación del agua extraída por la cubierta con el agua recibida por el riego. Sin embargo, en la parcela P2, la sonda muestra una ascensión de los valores, al igual que el agotamiento de agua en el suelo, debido a que tras un parón en el riego durante la primera semana de agosto, se trató de recuperar los niveles previos. Esta evaluación ofrece otro punto de apoyo más en la adecuación de la metodología empleada.
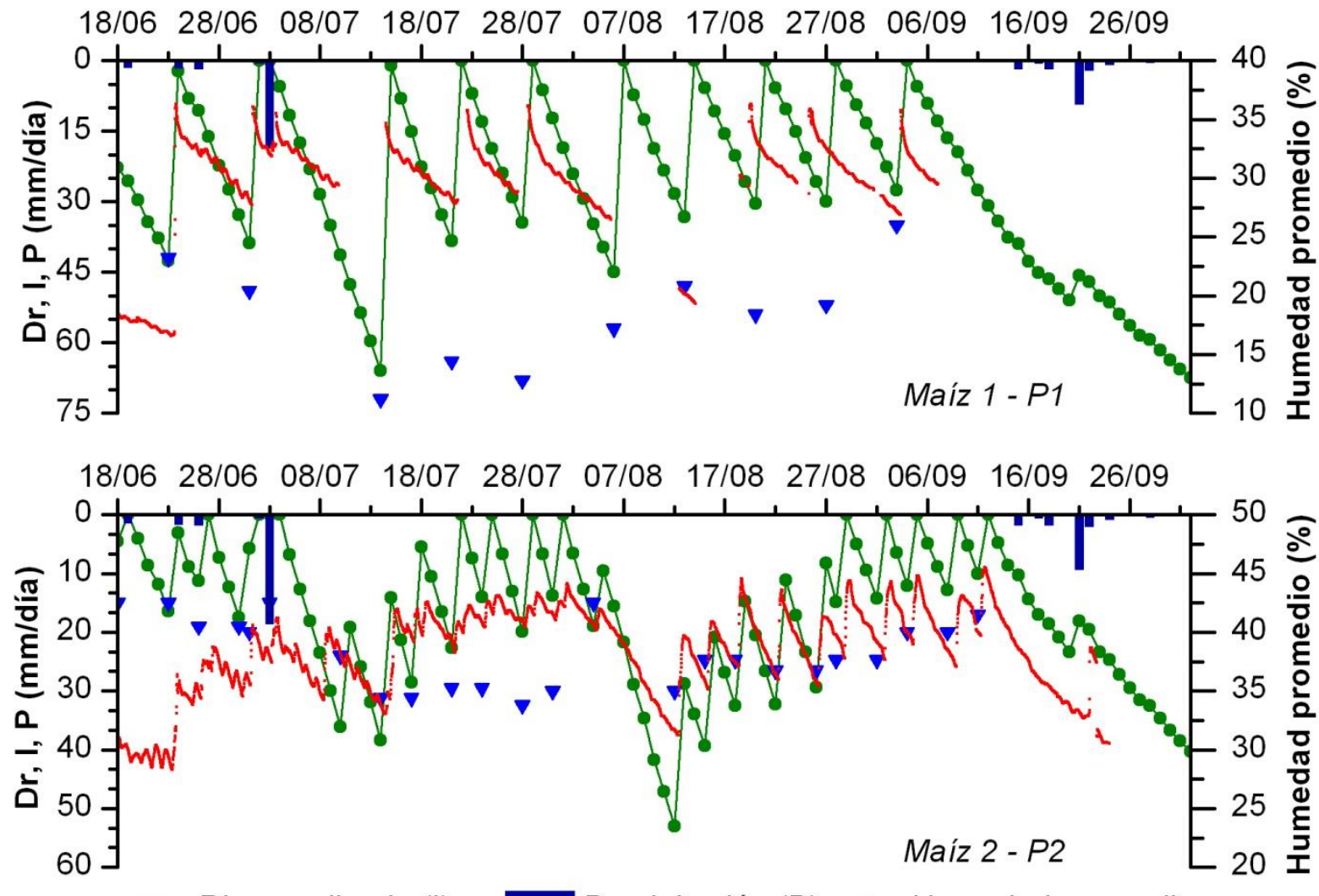

- Riego aplicado (I) $\square$ Precipitación $(\mathrm{P})$. Humedad promedio $\longrightarrow$ Agotamiento de agua en el suelo (Dr)

Figura 5. Evolución del agotamiento de agua en el suelo en la zona de raíces según los riegos aplicados en la parcela P1 (arriba) y P2 (abajo). 


\section{2- Limitaciones a la metodología}

Como ya se ha descrito previamente, la experiencia tuvo lugar desde el 18 de junio al 2 de octubre del 2014. Al comienzo de la monitorización, el cultivo de maíz ya había sido sembrado y se situaba aproximadamente en el día 40 de su desarrollo. Consecuentemente, había superado la fase inicial, encontrándose alrededor de la zona central de la fase de desarrollo (valores tabulados de duración de las fases recogidas por el manual FAO56). Con ello, la metodología presentada de coeficiente de cultivo único es apropiada por la alta cobertura del suelo que el cultivo herbáceo presenta, que limita en gran medida la evaporación desde el suelo desnudo tras eventos de riego o precipitación.

Sin embargo, para el establecimiento del cultivo, la relación NDVI - $\mathrm{K}_{\mathrm{c}}$ presentada en la ecuación 3 puede infra estimar el valor del $\mathrm{K}_{c}$. Esto es debido a que el cultivo, aún en fase de nascencia, no presenta una cobertura del suelo suficiente por lo que el comportamiento evaporativo del mismo es muy dominante, teniendo en cuenta además que durante dicha fase los riegos suelen ser frecuentes con el fin de garantizar la nascencia e implantación (FAO56). Análogamente, dicha relación podría no ser la más apropiada en cultivos cuya cobertura del suelo no es muy abundante incluso en su fase de meseta. Es el caso de ciertos cultivos hortícolas como cebollas, ajos, etc... donde además, por su escaso desarrollo radicular, requieren de riegos cortos y muy frecuentes para evitar que se agote rápidamente el agua en el suelo explorado por la raíces.

Por consiguiente, cuando la fracción de suelo desnudo es importante sería recomendable seguir la metodología de coeficiente de cultivo dual y estimar de forma independientemente la evaporación del suelo desnudo y la transpiración, lo que permite además diferenciar con el sistema de riego y por lo tanto la superficie efectivamente mojada. La simulación de la evaporación desde el suelo desnudo es uno de los aspectos que más desarrollo ha requerido desde la publicación del manual FAO56 (Allen, 2011; Torres and Calera, 2010). Por tanto, en muchos casos suele ser adecuado determinar la transpiración máxima de la cubierta mediante imágenes y aproximarse de forma específica al análisis de la componente evaporativa del suelo.

\section{4- Conclusiones}

La monitorización de cultivos mediante series temporales de imágenes de satélite ha permitido la extrapolación del $\mathrm{K}_{\mathrm{c}}$. Paralelamente, la predicción de las temperaturas por la AEMET abre la posibilidad de predecir la ETo mediante la ecuación de Hargreaves. Consecuentemente, la combinación de ambos factores en la metodología $K_{c}-E T_{0}$ ha permitido realizar la predicción semanal de las necesidades hídricas de los cultivos o $\mathrm{ET}_{\text {c }}$. Por tanto, se han podido programar los riegos a 7 días vista sobre los cultivos de maíz del CENTER según valores de $\mathrm{K}_{\mathrm{c}}$ adaptados a la zona de estudio.

Debido a una ligera sobreestimación de las necesidades hídricas consideramos importante realizar periódicamente una corrección sistemática de las predicciones. Se recomienda obtener el $\mathrm{K}_{\mathrm{c}}$ tras la pasada del satélite, y emplear la $E T_{\text {o }}$ medida por la red SIAR. La sustitución de ambos parámetros por los empleados en la correspondiente predicción permitirá ajustar las necesidades hídricas del cultivo en la próxima predicción.

La extensión de la metodología podría contribuir a la mejora en la eficiencia del uso de agua en el regadío español, potenciando el papel clave que tiene la red SIAR en la mejora de dicha eficiencia, utilizando para ello secuencias temporales de imágenes de 
satélite, la propia red SIAR, y distribuyendo productos y servicios a los usuarios mediante herramientas WebSIG. Pretende también contribuir a responder a las demandas que las políticas europeas establecen en el uso del agua.

\section{5- Agradecimientos}

El proyecto, financiado por la DGDRPF del MAGRAMA a través del Plan de Actividades del CENTER, se presenta en el marco de las acciones para innovación en los servicios de asesoramiento al regante mediante herramientas basadas en la red SIAR, teledetección y SIG, para un uso más eficiente del agua en el regadío. Queremos agradecer al personal del CENTER la buena disposición de medios y aptitudes para llevar a cabo la experiencia. Agradecer además la política de descarga libre y gratuita de imágenes del satélite Landsat puesta en práctica por el USGS.

\section{6- Bilbliografia}

AEMeT, Predicción por municipios. Agencia Estatal de Meteorología, Madrid.

Allen, R., Pereira, L.S., Raes, D., Smith, M., 1998. Crop evapotranspiration - Guidelines for computing crop water requirements - FAO Irrigation and drainage paper 56. FAO, Roma, Italy.

Allen, R.G., 2011. Skin layer evaporation to account for small precipitation events-An enhancement to the FAO-56 evaporation model. Agricultural Water Management 99, 8-18.

Campos, I., Odi, M., Belmonte, M., Martínez-Beltrán, C., Calera, A., 2011. Obtención de series multitemporales y multisensor de índices de vegetación mediante un procedimiento de normalización absoluta, XIV Congreso de la Asociación Española de Teledetección, Mieres, Asturias, Spain, p. 4.

Cuesta, A., Montoro, A., Jochum, A.M., López, P., Calera, A., 2005. Metodología operativa para la obtención del coeficiente de cultivo desde imágenes de satélite. ITEA : Información Técnica Económica Agraria 101, 212-224.

Chander, G., Markham, B.L., Helder, D.L., 2009. Summary of current radiometric calibration coefficients for Landsat MSS, TM, ETM+, and EO-1 ALI sensors. Remote Sensing of Environment 113, 893-903.

Garrido-Rubio, J., Rodriguez, J., Madurga, C., Fraile, L., Calera, A., González, L., JiménezMartinez, N., Arellano, I., Campos, I., Odi, M., Moreno-Rivera, J.M., 2012. Integración de la red SiAR e imágenes de satélite en la estimación de las necesidades de agua de riego. Aplicación al Center y su extensión a grandes áreas, XXX Congreso Nacional de Riegos, Albacete, p. 10.

Hargreaves, G.H., Samani, Z.A., 1985. Reference crop evapotranspiration from temperature. Applied Engineering in Agriculture 1 (2), 4.

MAGRAMA, 2014. SiAR, Sistema de información Agroclimática para el Regadio.

Rouse, J.W., Haas, R.H., Deering, D.W., Schell, J.A., 1973. Monitoring the vernal advancement and retrogradation of natural vegetation. Remote Sensing Center. College Station.

Torres, E.A., 2010. El modelo FAO-56 asistido por satélite en la estimació $n$ de la evapotranspiració $n$ en un cultivo bajo estrés hídrico y en suelo desnudo. Universidad de Castilla-La Mancha (UCLM).

Torres, E.A., Calera, A., 2010. Bare soil evaporation under high evaporation demand: a proposed modification to the FAO-56 model. Hydrological Sciences Journal 55, 303-315. 